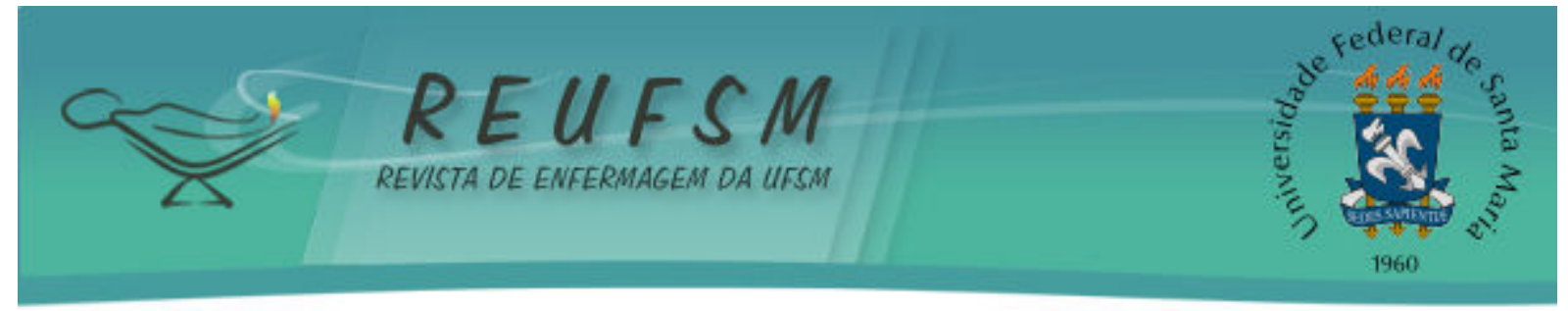

ARTIGO ORIGINAL

\title{
CONTOS INFANTOJUVENIS: UMA PRÁTICA LÚDICA DE HUMANIZAÇÃO PARA CRIANÇAS HOSPITALIZADAS
}

\section{CHILDREN'S AND JUVENILE TALES: A PLAYFUL PRACTICE OF HUMANIZATION FOR HOSPITALIZED CHILDREN}

\section{CUENTOS INFANTILES: UNA PRÁCTICA LÚDICA DE HUMANIZACIÓN PARA NIÑOS HOSPITALIZADOS}

Doi: 10.5902/2179769212071

\author{
Elaine Cristina Rodrigues Gesteira ${ }^{1}$ \\ Elaine Cristina Dias Franco ${ }^{2}$ \\ Patrícia Pinto Braga ${ }^{3}$ \\ Maria Beatriz Rodrigues Criscuolo ${ }^{4}$ \\ Jéssica Silva Oliveira ${ }^{5}$
}

RESUMO: Objetivo: compreender as reações das crianças hospitalizadas e de suas famílias ao ouvirem histórias infantis durante a execução do projeto de extensão e pesquisa: "Contos infantojuvenis: uma interface com a humanização do cuidado na hospitalização". Método: estudo descritivo e qualitativo usando o método observacional. Participaram do estudo 12 crianças hospitalizadas e suas famílias. Os dados foram coletados por meio da observação participante e registros de campo; em seguida, foram analisados fazendo emergir três categorias. Resultados: houve a evidência de que as crianças apresentam diferentes reações ao ouvir as histórias como mudança no humor, na postura corporal e facial. Além disso, notou-se que a família da criança hospitalizada valoriza essa prática lúdica como um momento de alegria e entusiasmo. Conclusões: o estudo revela a necessidade de práticas lúdicas que humanizem o ambiente pediátrico e auxiliem a criança e sua família na hospitalização.

Descritores: Criança hospitalizada; Humanização da assistência; Desenvolvimento infantil; Jogos e brinquedos.

ABSTRACT: Objective: to understand the reactions of hospitalized children and their families as they listen to children's stories during the activities of the research and extension project: "Children's and Juvenile Tales: an interface with the humanization of care in hospital". Method: this is a descriptive and qualitative study which used the observational method. Twelve children in hospital and their families participated in the study. Data were collected from participant observation and field record and then analyzed, giving rise to three categories. Results: there was evidence that children have different reactions while listening to the stories, such as changes in mood, body language

1. Professora Assistente do Curso de Enfermagem da Universidade Federal de São João del Rei- UFSJ.Mestre em Ciências da Saúde. Doutoranda em Enfermagem pela Universidade de São Paulo- USP. Divinópolis-Minas Gerais, Brasil. E-mail: ecr.gesteira@usp.br.

2. Professora Assistente do Curso de Enfermagem da Universidade Federal de São João del Rei- UFSJ. Mestre em Ciências. Doutoranda em Enfermagem pela Universidade Federal de Minas Gerais-UFMG. Divinópolis - Minas Gerais, Brasil. E-mail: elainefranco1@yahoo.com.br

3. Professora Adjunta do Curso de Enfermagem da Universidade Federal de São João del Rei-UFSJ. Mestre em Enfermagem. Doutora em Enfermagem pela Universidade Federal de Minas Gerais-UFMG. Divinópolis - Minas Gerais, Brasil. E-mail: patriciabragaufsj@gmail.com

4. Discente do Curso de Enfermagem da Universidade Federal de São João del Rei-UFSJ. Divinópolis - Minas Gerais, Brasil. E-mail: beatrizrodriguesc@hotmail.com

5. Discente do Curso de Enfermagem da Universidade Federal de São João del Rei-UFSJ. Divinópolis - Minas Gerais, Brasil. E-mail: jehh--@hotmail.com 


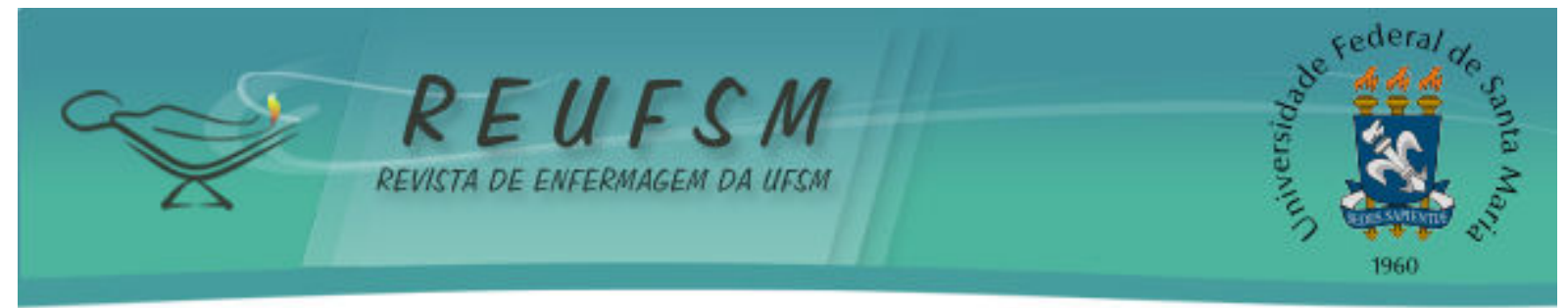

and facial expressions. Furthermore, it was noticed that the hospitalized child's family appreciates this playful practice as a moment of joy and enthusiasm. Conclusions: the study reveals the need for playful practices that humanize the pediatric environment and assist the child and their family in the hospitalization.

Descriptors: Child, hospitalized; Humanization of assistance; Child development; Play and playthings.

RESUMEN: Objetivo: comprender las reacciones de los niños hospitalizados y sus familias al escuchar historias infantiles durante la ejecución del proyecto de investigación y extensión universitaria: "Cuentos infantiles: una interfaz con la humanización de la atención en la hospitalización." Método: estudio descriptivo y cualitativo utilizando el método de observación. Participaron en el estudio 12 niños hospitalizados y sus familias. Los datos fueron recolectados a través de observación participante y registro de campo; luego fueron analizados, surgiendo tres categorías. Resultados: hubo evidencia de que los niños tienen diferentes reacciones a escuchar las historias como cambios en el estado de ánimo, en la postura corporal y facial. Además, se notó que la familia del niño hospitalizado valora esta práctica lúdica como un momento de alegría y entusiasmo. Conclusiones: el estudio revela la necesidad de prácticas lúdicas que humanicen el entorno pediátrico y apoyen a los niños y familias en la hospitalización.

Descriptores: Niño hospitalizado; Humanización de la atención; Desarrollo infantil; Juego e implementos de juego.

\section{INTRODUÇÃO}

A hospitalização é um evento estressante para a criança e sua família; diferentes sentimentos e comportamentos afloram nessa fase como insegurança, medo, ansiedade, nervosismo, preocupação, angústia, estresse psicológico, temor, pânico, choro e agitação. ${ }^{1}$ A criança hospitalizada não apresenta apenas angústia relacionada à doença, mas também sente o medo do desconhecido que a própria hospitalização desencadeia, deixando-a duplamente doente no que tange aos aspectos biopsicossociais.

O sofrimento da criança durante a hospitalização é um fato que não pode ser evitado totalmente, pois é a resposta a esse contexto que the é ameaçador, incerto e que surge em sua vida de forma abrupta. A criança é colocada em uma situação para a qual não está preparada e precisa compreendê-la de acordo com o grau de seu desenvolvimento. ${ }^{2-3}$

Nesse sentido, a fim de amenizar as repercussões advindas da hospitalização, a criança necessita de um meio lúdico como suporte para a compreensão, o tratamento e seu desenvolvimento..$^{3-5}$ As práticas lúdicas como a música, animação clown, contos infantis, brinquedoteca, entre outras, reforçam a premissa de que a criança não deve parar de brincar quando se encontra hospitalizada. Ressalta-se que o brincar e o imaginar devem acompanhar o atendimento pediátrico compondo uma assistência humanizada.

$\mathrm{Na}$ atual conjuntura do Programa Nacional de Humanização da Atenção e Gestão do SUS - o HumanizaSUS há uma busca pela efetivação de um dos princípios do Sistema Único de Saúde (SUS): de humanizar o atendimento ao usuário ${ }^{6}$ ressaltando-se, dessa maneira, o compromisso dos profissionais de saúde em criar espaços e atividades lúdicas que permitam a mediação de uma assistência digna e de qualidade às crianças. Para isso, estudo $^{7}$ aponta para a necessidade de estratégias que contemplem o lúdico, de forma a tornar o ambiente hospitalar pediátrico um lugar menos traumatizante e mais alegre. 


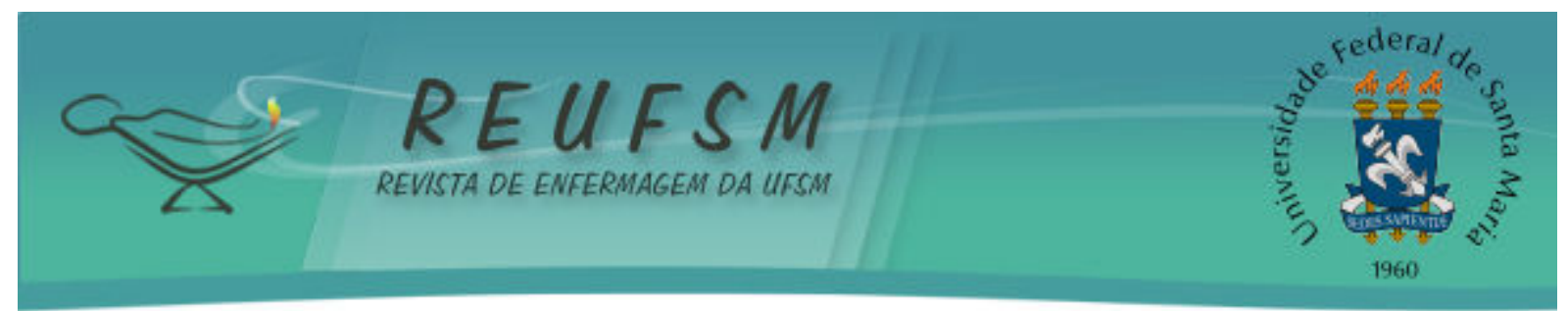

Nessa perspectiva, estudiosos ${ }^{8}$ revelaram que a atenção dispensada a pacientes pediátricos auxilia na superação de traumas, estimulando a alegria pela vida como parte integrante de seu desenvolvimento.

Os profissionais de saúde que lidam com a criança no ambiente hospitalar devem estar preparados para um trabalho multidisciplinar que favoreça um atendimento humanizado às crianças e suas famílias que, no momento da hospitalização, sentem sua autonomia ameaçada. ${ }^{1}$

Para tanto, faz-se necessário entender que os elementos como a valorização do outro, o respeito, a compreensão, o envolvimento estabelecido pelo profissional e o cliente no processo de cuidado fazem parte de um complexo entendimento sobre a humanização, sua aplicabilidade e efetividade na gestão dos serviços. ${ }^{9}$

Acredita-se que no espaço pediátrico, é imprescindível criar mais propostas de intervenção, com atividades lúdicas que minimizem o impacto da hospitalização na infância. Nesse contexto, houve uma iniciativa de docentes e discentes do curso de Enfermagem da Universidade Federal de São João Del Rei-UFSJ em criar o projeto de extensão e pesquisa intitulado "Contos Infantojuvenis: uma interface com a humanização do cuidado na hospitalização" reforçando as práticas lúdicas já existentes no setor pediátrico de um hospital filantrópico do centro-oeste do estado de Minas Gerais.

A partir da vivência das pesquisadoras com as atividades de extensão, surgiu uma condição que favoreceu além do ato de contar histórias, a oportunidade de observar as reações das crianças durante essa prática. Assim, a cada intervenção, uma das pesquisadoras fez o papel de "observador", o que contribuiu para criar registros com anotações de cada intervenção. Frente ao exposto, justifica-se o seguinte questionamento: Como as crianças hospitalizadas e os familiares acompanhantes reagem em relação à intervenção lúdica dos contos infantojuvenis? Desse modo, o presente estudo teve como objetivo compreender as reações das crianças hospitalizadas e de suas famílias ao ouvirem histórias infantis durante a execução do projeto de extensão e pesquisa: "Contos infantojuvenis: uma interface com a humanização do cuidado na hospitalização".

\section{MÉTODO}

Trata-se de um estudo descritivo com abordagem qualitativa. Esse tipo de investigação permite apreender o significado de elementos que não podem ser quantificados, mas valoriza dados subjetivos dos sujeitos qualificando-os durante a pesquisa. ${ }^{10}$

Dessa maneira, a presente pesquisa ao ser desenvolvida no cenário do projeto de extensão, propiciou aos pesquisadores, a observação e o registro das reações das crianças e de suas famílias ao ouvirem as narrativas dos clássicos infantis, enquanto outros componentes do grupo conduziam a atividade de narrar as histórias.

Todo o processo de construção levou em consideração as diretrizes da Resolução 196/96 do Conselho Nacional de Saúde que regulamenta a pesquisa envolvendo seres humanos. O projeto foi aprovado pelo Comitê de Ética em Pesquisa (CEP) da instituição cenário obtendo o parecer de número no 44/2011; protocolo CEP-HSJD:184.

O cenário da prática lúdica foi um setor pediátrico com 35 leitos de um hospital filantrópico do município de Divinópolis, Minas Gerais, referência para a macrorregião oeste mineira. Participaram do estudo, 12 crianças acompanhadas por um membro da família que, coincidentemente, eram mães e pais dos observados. Quando os dados se tornaram repetitivos, interrompeu-se a coleta. 


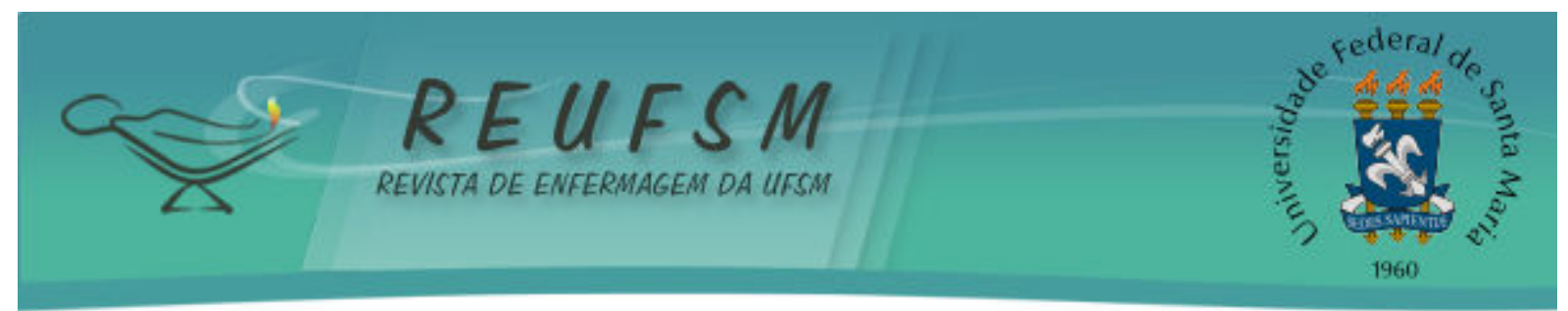

A coleta de dados ocorreu no período de maio de 2011 a junho de 2012, no período diurno, respeitando-se a rotina da unidade, os horários de dieta e repouso das crianças, a fim de garantir a participação das mesmas.

As práticas foram executadas à beira do leito com narrativas que duravam entre 20 e 30 minutos, a partir do uso de livros infantis e, em algumas, com uso de contação de histórias sem a demonstração do livro; em outras oportunidades, as histórias eram recontadas e reinventadas de acordo com a solicitação das crianças.

Considerando a peculiaridade de observar as reações das crianças hospitalizadas e de suas famílias ao ouvirem histórias infantis e de buscar compreendê-las, optou-se pela observação participante ${ }^{11}$ como método, por se entender que as pesquisadoras participaram da vivência dos sujeitos, o que oportunizou a criação de um registro de campo não estruturado, como já mencionado, que continha apenas dados como iniciais do nome das crianças, idade, diagnóstico, tempo de internação e data das atividades dos contos. O outro espaço para registro das reações era livre para as anotações das observadoras. Anexo aos registros havia o Termo de Consentimento Livre e Esclarecido assinado pelos pais das crianças.

Os métodos observacionais são utilizados para compreender um grupo; portanto o pesquisador vivencia o cotidiano desses sujeitos tendo contato prolongado com o ambiente. ${ }^{11}$ Para participar do estudo utilizaram-se como critérios de inclusão as crianças com idade entre três e 12 anos, por ser a faixa etária prevalente na unidade pediátrica, as que estivessem acamadas ou não e aquelas cujos pais concordaram em que participassem da sessão após a assinatura do Termo de Consentimento Livre e Esclarecido. Não foram inclusas no presente estudo crianças sedadas, crianças que estivessem com dor e aquelas que estivessem sendo submetidas a procedimentos hospitalares no momento da leitura dos contos.

Para analisar os dados optou-se pela análise de conteúdo ${ }^{12}$ que por meio das etapas de pré-análise, exploração do material, inferência e interpretação dos resultados, permitiu discutir as reações das crianças hospitalizadas à atividade lúdica dos contos.

Após a leitura flutuante do material, foram identificadas as reações observadas; em seguida, guiando-se pelos padrões de análise de conteúdo, foi realizada a leitura exaustiva do material visando abstrair as anotações de campo que contemplavam o objetivo da pesquisa; na sequência, realizou-se a exploração do material a fim de analisar os dados emergidos pelos sujeitos pesquisados. Para preservar o anonimato, os participantes foram identificados por nomes fictícios de histórias infantis seguidos das idades.

$\mathrm{Na}$ etapa seguinte, foi realizada a codificação do material buscando agregar as mesmas unidades de sentido, ou seja, a agregação das reações anotadas que foram semelhantes e que possuíam os mesmos significados. Em seguida, conforme revelado no estudo, categorizaram-se os dados em três temas, buscando compreender as mensagens neles contidas a fim de interpretar esses achados e discuti-los de acordo com as produções científicas sobre a temática.

\section{RESULTADOS E DISCUSSÃO}

A partir da análise, os dados foram interpretados em três categorias.

\section{Ouvir histórias estimula o imaginário e modifica o humor das crianças}

Nota-se que sentimentos nas crianças afloram com gestos de sorrisos, alegria, felicidade, satisfação e esperança como observado a seguir: 


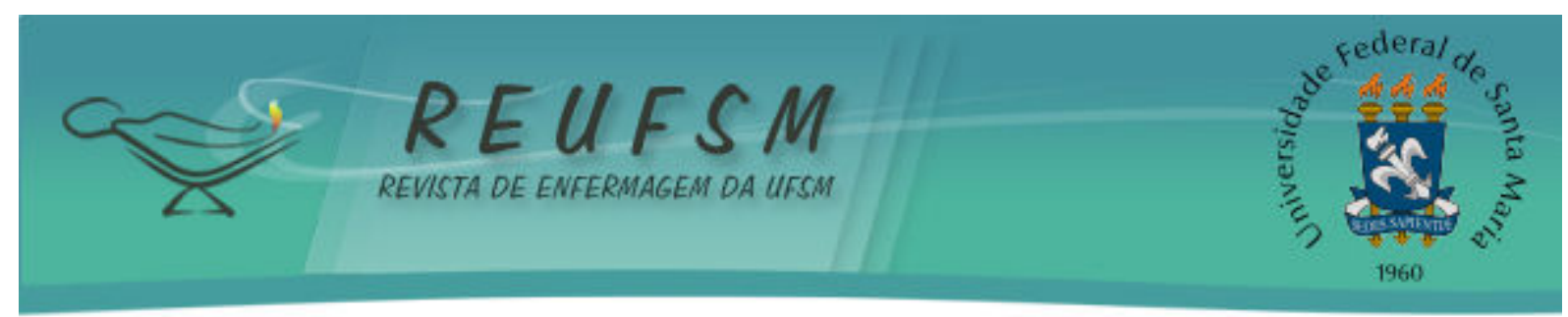

Antes dos contos, a criança estava deitada e desanimada e durante a leitura sentou-se para ouvir e mostrou entusiasmo com leves sorrisos [...] (Saci, 10 anos)

Antes da mediação, a criança apresentava-se quieta e calada. Durante a leitura, a criança sorria e apresentou interesse. Após a leitura, a criança ficou mais comunicativa e brincou com seus brinquedos. (Mágico de Oz, 3 anos)

Ao chegarmos, apresentava-se aparentemente triste. Durante a história, ficou interessado e acabou ajudando a contar a história, ficando mais comunicativo. (Minnie, 10 anos)

Antes da atividade lúdica: a criança sorriu, mudando de aparência, pois antes estava quieta e calada, ajudou na escolha da história e apresentou ansiedade para o inicio [...] a criança interage mostrando estar gostando e entendendo a história. Pede para que um livro dela seja lido e demonstra felicidade. Depois mostrou ter gostado e estava conversando sobre a mediação contando o que aconteceu. (Pumba, 10 anos)

Antes dos contos estava deitado em seu leito e quando chegamos demonstrou interesse nas leituras sorrindo. Durante os contos participava nas falas da história; ao final mostrou-se satisfeito e pediu que contássemos outras histórias. (Pequeno Príncipe, 7 anos)

0 processo de hospitalização infantil traz consequências marcantes na vida da criança porque a partir de sua internação ela sai de seu cotidiano e passa a vivenciar momentos de dúvidas e apreensão acerca da doença e de seu tratamento. Para os pais fica ainda a difícil tarefa de acompanhar o filho durante esse período, além de temer por seu futuro.

A criança e sua família passam a vivenciar diferentes tipos de comportamentos de acordo com o prognóstico da doença e de como a criança está enfrentando esse momento. Logo, sentimentos múltiplos podem ser observados como: desânimo, angústia, medo, agitação, frustração, descrença, esperança, entre outros. Esses comportamentos frente à hospitalização influenciam diretamente na reabilitação da saúde da criança dentro do ambiente hospitalar. ${ }^{13}$

Assim, intervir nesse processo com atividades lúdicas, faz com que a dor e o sofrimento sejam ao menos por um breve momento esquecidos, o que auxilia a criança e sua família a enfrentar as adversidades da rotina hospitalar. Foi observado neste estudo que durante as mediações dos contos infantis, houve variações de humor e de expressão corporal e facial das crianças, o que permite dizer que essa prática é uma ferramenta lúdica útil no ambiente hospitalar pediátrico, porque é capaz de mobilizar sentimentos e de estimular a criança a sair de sua condição passiva para se integrar ao meio, ou seja, ela consegue perceber que há momentos que podem ser prazerosos no ambiente que lhe era hostil, além de estimular o seu desenvolvimento.

Como já mencionado anteriormente, o hospital para a criança é um ambiente desconhecido e, muitas vezes, assustador. ${ }^{14}$ Entretanto, neste estudo percebe-se que a atividade lúdica de contar histórias para a criança hospitalizada modificou seu cotidiano no hospital, o que pode ter gerado mudanças no humor pelo imaginário estimulado pela leitura. 


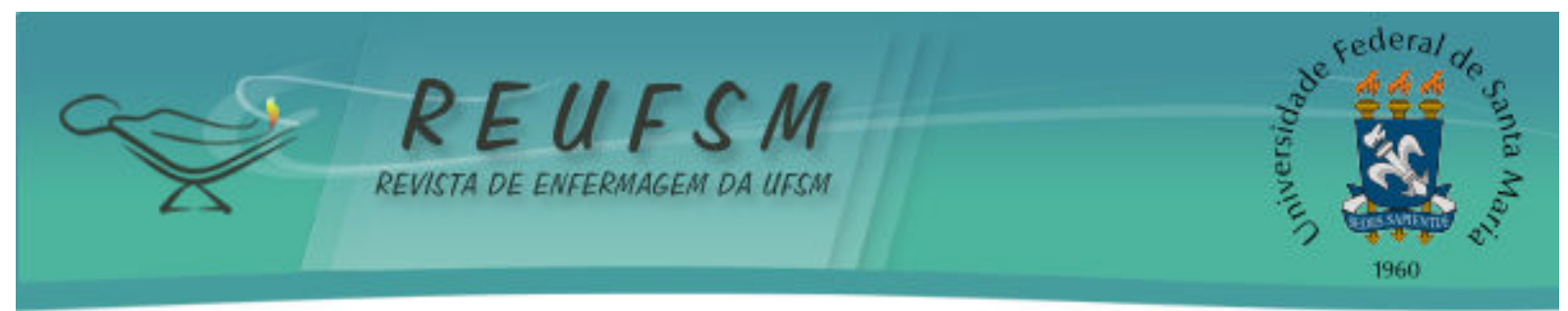

Percebe-se que esse momento de ludicidade modifica a rotina do setor pediátrico tornando-o menos hostil, menos solitário e gerador de sentimentos como: felicidade, ânimo, interesse, esperança, entre outros.

É possível perceber que as crianças saem de um estado aparentemente depressivo e melhoram a autoestima; a leitura estimula o resgate do sonho e da fantasia do mundo encantado. ${ }^{15}$

\section{Os contos infantojuvenis como estímulo terapêutico}

Conforme descrição abaixo é perceptível que a criança após a atividade lúdica ficou mais responsiva frente aos cuidados realizados no âmbito hospitalar.

Tranquilo no decorrer da história, deixando os profissionais fazerem os procedimentos necessários. (João pé de feijão, 5 anos)

Ao ouvir as histórias infantis, a criança tem a oportunidade de pensar e expor sentimentos e quando as histórias são voltadas para questões de saúde, é ainda melhor porque a criança percebe que não está sozinha em seu sofrimento. ${ }^{16}$ Desse modo, os contos proporcionam bem-estar aos ouvintes e assim é possível observar que as crianças ficam mais tranquilas diante dos procedimentos hospitalares.

Nesse sentido, o conto favorece a introspecção e, por meio dele, a criança tem a possibilidade de interpretar que o sofrimento é passageiro, o que contribui com o tratamento clínico para o alcance de resultados positivos diante da doença. A partir da interação da criança com os contos, é possível personalizar o atendimento e contribuir de forma positiva para a qualidade da assistência.

\section{A atividade lúdica dos contos e sua interface com a humanização da assistência à criança e à sua família}

As observações sequenciais revelam que a atividade lúdica de contar histórias para as crianças hospitalizadas estimula a interação entre a criança e sua família:

Houve grande interação entre a criança, a família e as voluntárias do projeto. (Cinderela, 9 anos)

[...] mãe relata que a criança estava desanimada com o tratamento; após os contos, a criança aceitou melhor o tratamento hospitalar. (Alice no país das maravilhas, 10 anos)

[...] mãe relata que, depois da mediação, a criança conta a história para o pai no telefone. (Narizinho, 5 anos)

[...] os pais ficaram muito emocionados com a mediação, relataram que trouxemos um pouco do que ela tem em casa para o hospital que são os contos infantis. (Chapeuzinho vermelho, 5 anos)

A internação, como revelado anteriormente, suscita nas crianças, sentimentos de insegurança e apreensão o que, por sua vez, interfere na recuperação da saúde desse grupo. Desse modo, estudos ${ }^{7,17}$ reforçam a necessidade de estratégias que contemplem o lúdico, de forma a tornar o ambiente hospitalar pediátrico um lugar menos traumatizante e mais alegre. 


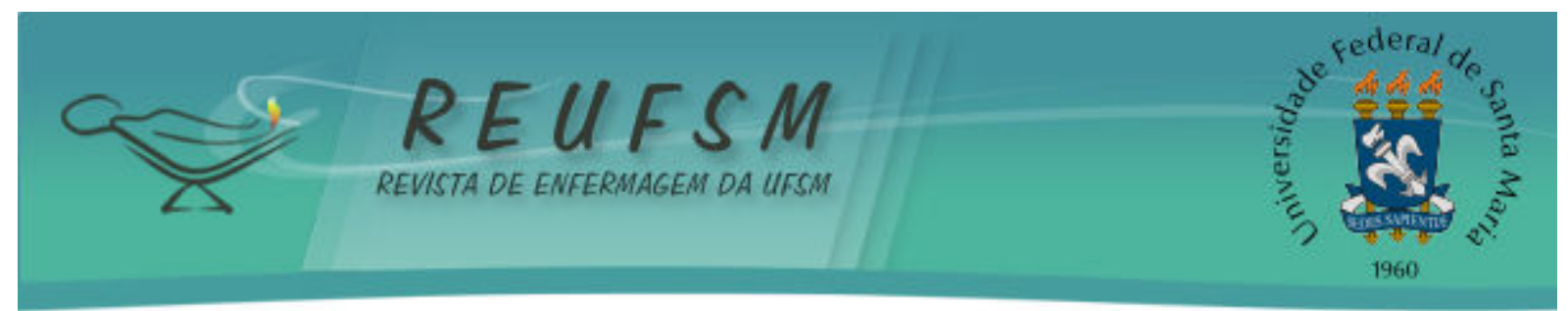

Sendo a humanização um processo, um modo de prestar a assistência ao indivíduo e sua família na dimensão do cuidado $^{18}$, reafirma-se a necessidade de se considerarem cada vez mais as questões afetivas, emocionais e sociais da criança, criando espaços de brincadeiras, leituras, músicas e jogos que efetivem a humanização desse ambiente, o que auxilia crianças e pais a enfrentarem os períodos de vulnerabilidade.

No contexto da hospitalização, é fundamental o apoio da família na recuperação da criança ${ }^{19-20}$, mas também é necessário um movimento que permita a participação dos pais em projetos e programas interinstitucionais que estimulam a humanização por meio de práticas lúdicas.

As atividades lúdicas voltadas às crianças são essenciais para o enfrentamento dos aspectos biopsicossociais que envolvem o cotidiano da família que está fragmentada pela doença e hospitalização. Desse modo, os contos infantojuvenis trazem às crianças e a seus pais, momentos de descontração que tornam o cuidado participativo e humanizado.

\section{CONSIDERAÇÕES FINAIS}

O estudo permitiu compreender que a atividade lúdica de contar histórias para crianças hospitalizadas favorece o bem-estar físico, emocional e psíquico dos envolvidos. Identificaram-se reações como alegria, entusiasmo, descontração e entretenimento. Além disso, a atividade lúdica dos contos infantis foi identificada como elemento importante para o alcance da estratégia de humanização porque permitiu aos pais e às crianças momentos de interação, proporcionando-lhes um ambiente pediátrico mais harmonioso e menos ameaçador diante da realidade da doença.

Considera-se que a criança e sua família são direcionadas a um cuidado humanizado, o que favorece o enfrentamento da doença e da hospitalização. Nesse contexto, o método observacional revelou que as crianças mudaram o humor após participarem dos momentos de contos tornando-se mais participativas, o que pode potencialmente contribuir em sua recuperação.

Embora haja amplos estudos sobre a importância da atividade lúdica em pediatria, este estudo corrobora para o resgate de contar histórias para crianças momentaneamente doentes, afastadas de seu cotidiano, das brincadeiras, de atividades escolares, e que necessitam também do imaginário para favorecer o seu desenvolvimento.

\section{REFERÊNCIAS}

1. Carvalho LS, Silva CA, Oliveira ACP, Camargo CL. O interacionismo simbólico como fundamento para pesquisas de enfermagem pediátrica. Rev Enferm UERJ. 2007;15(1):11924.

2. Nóbrega RD, Collet N, Gomes IP, Holanda ER, Araújo YB. Criança em idade escolar hospitalizada: significado da condição crônica. Texto \& Contexto Enferm [Internet]. 2010 jul/set [acesso em 2013 jul 3];19(3):425-33. Disponível em: http: / / www.scielo.br/scielo.php?script=sci_arttext\&pid=S0104-

$07072010000300003 \& \operatorname{lng}=$ pt\&nrm=iso\&tlng=pt doi: 10.1590/S0104-07072010000300003.

3. Ribeiro CR, Pinto Junior AA. A representação social da criança hospitalizada: um estudo por meio do procedimento de desenho-estória com tema. Rev SBPH. 2009;12(1):31-56.

4. Ribeiro CA, Angelo M. O significado da hospitalização para a criança pré-escolar: um modelo teórico. Rev Esc Enferm USP [Internet]. 2005 dez [acesso em 2013 jul 6];39(4): 391-400. Disponível em: http://www.scielo.br/scielo.php?script=sci_arttext\&pid=S008062342005000400004\&lng=pt\&nrm=iso\&tlng=pt doi: 10.1590/S0080-62342005000400004. 


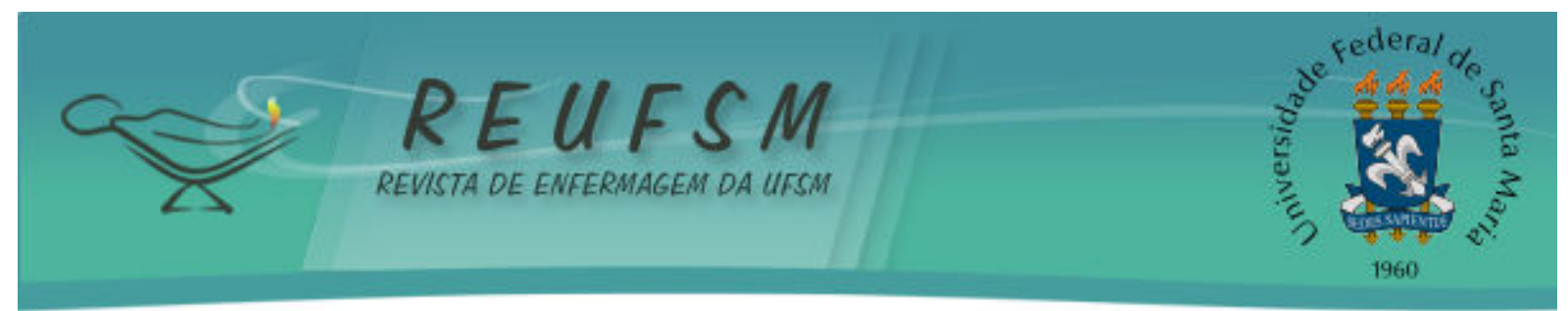

5. Gomes ILV, Câmara NAC, Lélis GFD, Grangeiro GFC, Jorge MSB. Humanização na produção do cuidado à criança hospitalizada: concepção da equipe de enfermagem. Trab Educ Saúde. 2011;9(1):125-35.

6. Brasil. Ministério da Saúde. Portal Saúde. Diretrizes para a implementação do HumanizaSUS [Internet]. [acesso em 2014 jun 12]. Disponível em: <http://portal.saude.gov.br/portal/saude/cidadao/visualizar_texto.cfm?idtxt=28345>.

7. Lima RAG, Azevedo EF, Nascimento LC, Rocha SMM. A arte do teatro Clown no cuidado às crianças hospitalizadas. Rev Esc Enferm USP [Internet]. 2009 mar [acesso em 2013 ago 15];43(1):186-93. Disponível

em:

http:/ / www.scielo.br/scielo.php?script=sci_arttext\&pid=S0080-

$62342009000100024 \&$ lng=pt\&nrm=iso\&tlng=pt.

8. Castanha ML, Lacerda MR, Zagonel IPS. Hospital: lugar para o enfermeiro cuidar do imaginário. Acta Paul Enferm. 2005;18(1):94-9.

9. Reis LS, Silva EF, Waterkemper R, Lorenzini E, Cecchetto FH. Percepção da equipe de enfermagem sobre humanização em unidade de tratamento intensivo neonatal e pediátrica. Rev Gaúcha Enferm [Internet]. 2013 jun [ acesso em 2014 jun 13];34(2):118124. Disponível em: http://www.scielo.br/pdf/rgenf/v34n2/v34n2a15.pdf.

http://dx.doi.org/10.1590/S1983-14472013000200015.

10. Pope $C$, Mays $N$, organizadores. Pesquisa qualitativa na atenção à saúde. Porto alegre: Artmed; 2009.

11. Pope C, Mays N. Métodos observacionais. In: Pope C, Mays N, organizadores. Pesquisa qualitativa na atenção à saúde. Porto Alegre: Artmed; 2009. p. 45-55.

12. Bardin L. Análise de contéudo. São Paulo: Editora 70; 2011.

13. Favero L, Dyniewicz AM, Spiller APM, Fernandes LA. A promoção do brincar no contexto da hospitalização infantil como ação de enfermagem: relato de experiência. Cogitare Enferm [Internet]. 2007 out/dez [acesso em 2013 jul 6];12(4):519-24. Disponível em: http://ojs.c3sl.ufpr.br/ojs2/index.php/cogitare/article/view/10080/6932.

14. Ceribelli C, Nascimento LC, Pacífico SMR, Lima RAG. A mediação de leitura como recurso de comunicação com crianças hospitalizadas. Rev Latinoam Enferm. 2009;17(1):81-7.

15. Moreno RLR, Diniz RLP, Magalhães EQ, Souza SMPO, Silva MSA. Contar histórias para crianças hospitalizadas: relato de uma estratégia de humanização. Rev Pediatria [Internet]. 2003 out [acesso em 2013 jul 10];25(4):164-9. Disponível em: http://pediatriasaopaulo.usp.br/upload/pdf/593.pdf.

16. Schneider REF, Torossian SD. Contos de fadas: de sua origem à clínica contemporânea. Psicol Rev [Internet]. 2009 ago [acesso em 2013 jul 10];15(20):132-48. Disponível em: http://pepsic.bvsalud.org/scielo.php?script=sci_arttext\&pid=S1677$11682009000200009 \& \operatorname{lng}=$ pt\&nrm=iso.

17. Mendes LR, Broca PV, Ferreira MA. A leitura mediada como estratégia de cuidado lúdico: contribuição ao campo da enfermagem fundamental. Esc Enferm Anna Nery Rev Enferm [Internet]. 2009 jul/set [acesso em 2013 ago 12];13(3):530-6. Disponível em: http://www.scielo.br/pdf/ean/v13n3/v13n3a11.pdf. Doi: D 10.1590/S141481452009000300011. 


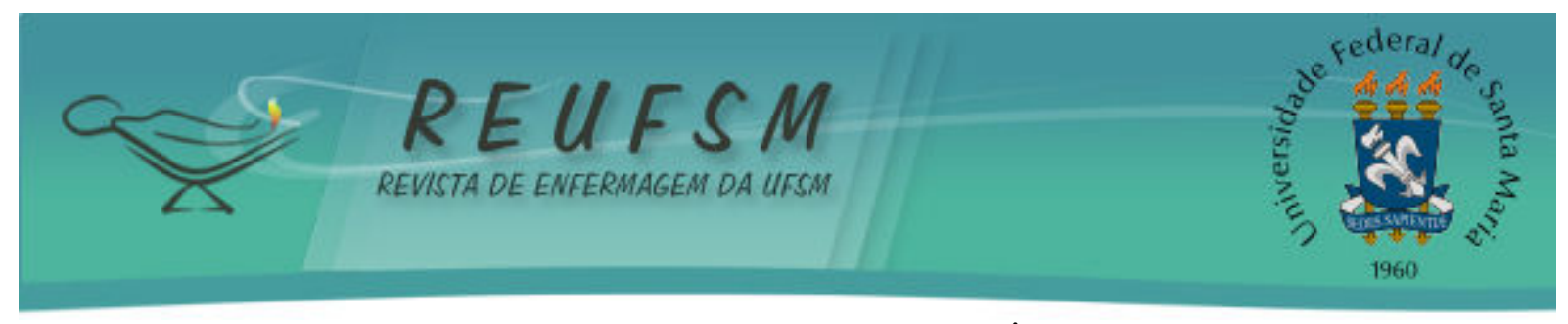

18. Lazzari DD, Jacobs LG, Jung W. Humanização da assistência na enfermagem a partir da formação acadêmica. Rev Enferm UFSM [Internet]. 2012 jan/abr [acesso em 2013 set 2];2(1):116-24. Disponível em: http://cascavel.ufsm.br/revistas/ojs2.2.2/index.php/reufsm/article/view/3705/3133.

Doi: http://dx.doi.org/10.5902/217976926918.

19. Silva TP, Leite JL, Santos NLP, Silva IR, Mendonça ACA, Santos MJC, et al. Cuidados de enfermagem à criança com câncer: uma revisão integrativa na literatura. Rev Enferm UFSM [Internet]. 2013 jan/abr [acesso em 2013 ago 16];3(1):68-78 Disponível em: http://cascavel.ufsm.br/revistas/ojs-2.2.2/index.php/reufsm/article/view/6918/pdf. Doi: http://dx.doi.org/10.5902/217976926918.

20. Santos LF, Oliveira LMAC, Barbosa MA, Siqueira KM, Peixoto MKAV. Reflexos da hospitalização da criança na vida do familiar acompanhante. Rev Bras Enferm [Internet]. 2013 ago [acesso em 2014 jun 14];66(4):473-8. Disponível em: http://www.scielo.br/pdf/reben/v66n4/v66n4a02.pdf.

http://dx.doi.org/10.1590/S0034-71672013000400002.

Data de recebimento: $28 / 11 / 2013$

Data de aceite: 15/08/2014

Contato com autor responsável: Elaine Cristina Rodrigues Gesteira

Endereço postal: Avenida Sebastião Gonçalves Coelho,400-Cep:35501-296-Divinópolis-MG

E-mail: ecr.gesteira@hotmail.com 